\title{
The association between COVID-19 and preterm delivery: A cohort study with a multivariate analysis
}

Author

Spanish Obstetric Emergency Group.

\section{Encompassing 45 hospitals}

\section{CORRESPONDING AUTHOR}

Oscar Martínez Pérez:oscarmartinezgine @ gmail.com

Department of Obstetrics and Gynaecology. Hospital Universitario Puerta de Hierro. Majadahonda, Madrid, Spain.

\section{Structured abstract}

Objective: To determine whether severe acute respiratory syndrome coronavirus 2 (SARS-CoV-2, the cause of COVID-19 disease) exposure in pregnancy, compared to non-exposure, is associated with infection-related obstetric morbidity.

Design and setting: Throughout Spain, 45 hospitals took part in universal screening of pregnant women going into labour using polymerase-chain-reaction (PCR) for COVID19 since late March 2020.

Methods: The cohort of exposed and unexposed pregnancies was followed up until 6weeks post-partum. Multivariate logistic regression analysis, adjusting for known confounding variables, determined the adjusted odds ratio (aOR) with $95 \%$ confidence intervals (95\% CI) of the association of COVID-19 exposure, compared to nonexposure, with infection-related obstetric outcomes.

Main outcome measures: Preterm delivery (primary), premature rupture of membranes and neonatal intensive care unit admissions.

Results: In the cohort of 1,009 screened pregnancies, 246 were COVID-19 positive. Compared to non-exposure, COVID-19 exposure increased the odds of preterm birth (34 vs $51,13.8 \%$ vs $6.7 \%$, aOR $2.12,95 \%$ CI $1.32-3.36, \mathrm{p}=0.002$ ), premature rupture of membranes at term (39 vs $75,15.8 \%$ vs $9.8 \%$, aOR $1.70,95 \%$ CI 1.11-2.57, $\mathrm{p}=0.013$ ) and neonatal intensive care unit admissions (23 vs $18,9.3 \%$ vs $2.4 \%$, aOR $4.62,95 \%$ CI $2.43-8.94, \mathrm{p}<0.001)$.

Conclusion: This first prospective cohort study demonstrated that pregnant women infected with SARS-CoV-2 have more infection-related obstetric morbidity. This hypothesis merits evaluation of a causal association in further research. 


\section{Introduction}

Severe acute respiratory syndrome coronavirus 2 (SARS-CoV-2), identified in December 2019, is the cause of the illness named COVID-19. ${ }^{1,2}$ With more than 249,000 confirmed cases and more than 28,700 deaths by $20^{\text {th }}$ August 2020, Spain remains one of the European countries most severely affected by the ongoing COVID19 pandemic. ${ }^{3,4}$ Spain also established a universal screening programme for pregnancies in light of the higher disease exposure. We observed that obstetric intervention may influence the clinical course of the disease. ${ }^{5}$ The cohort of pregnant women assembled through this programme lends itself to evaluation of concerns about obstetric outcomes.

The majority of non-pregnant patients with COVID-19 have uncomplicated or mild illness (81\%), some will develop severe illness associated with cytokine-mediated inflammation phenomena such as IL-6 associated with the need for mechanical ventilation. ${ }^{6}$ Initial studies have reported similar involvement in pregnant patients. ${ }^{7}$ The inflammatory mediators associated COVID-19 have previously been related to poor perinatal outcomes. ${ }^{8-9}$ This background naturally leads to the question as to whether COVID-19 affects pregnancy adversely.

We hypothesised that COVID-19 exposure in pregnancy, compared to non-exposure, would increase infection-related obstetric morbidity including preterm birth and premature rupture of membranes which in turn would increase the admissions of the neonate to intensive care units. We tested the hypothesis in a multivariate logistic regression analysis, adjusting for the effect of known confounding variables. 


\section{Materials and methods}

In March 2020, the Puerta de Hierro University Hospital in collaboration with 76 hospitals of several Spanish regions, launched OBS COVID REGISTRY, a populationbased, longitudinal observational and analytic study, to quantify the obstetrical and perinatal morbimortality possibly associated to COVID infection throughout Spain. ${ }^{10}$ Between the third week of March and the first week of May 2020, 45 hospitals started consecutive universal PCR screening of all patients going into labour (Figure 1).

\section{Ethics Committee Approval}

All procedures were approved by Puerta de Hierro University Hospital (Madrid, Spain) ethics committees (reference number, 55/20). All the 76 hospitals involved in the previously created Emergency Obstetrics Spain Group recognized and adopted the procedures. Written informed consent was obtained, sometimes in a delayed fashion, from the study patients at each centre when possible. The majority of the informed consents were provided verbally depending on local ethics committee regulations and special policies issued for Covid-19 research due to the pandemic situation. All verbal consents were recorded in the patient medical records. The registry protocol, including all the information on the variables under study, is available in the OSF website: https://osf.io/k82ja/?view_only=61d3773cc12f423b8568ff11acb0fa44We developed an analysis plan using recommended contemporaneous methods and followed existing guidelines for reporting. ${ }^{11}$ 


\section{Assembly of the cohort}

Case recruitment for this initial study ended on $31^{\text {st }}$ May 2020. Hospitals collected the encoded information in two separate phases: during the enrolment period that occurred at the time of the SARS-CoV-2 test during pregnancy and within 2 weeks after birth. Case eligibility criteria were pregnant patients with laboratory confirmation of COVID19 infection, irrespective of clinical signs and symptoms or the result of another serological test; positive RNA polymerase-chain-reaction (PCR) test from nasopharyngeal and/or oropharyngeal swabs from mother. In those cases, with a clinical presentation of COVID19, it was classified following the WHO division for adults: mild symptoms, mild-moderate pneumonia, severe pneumonia and septic shock. ${ }^{12}$ All identified cases were included in the study. The healthy cohort (comparison group not exposed to COVID-19) included pregnant women who were negative for the PCR test, who were selected in each center based on the delivery date of the cases, selecting deliveries before and/or after that of the case,with maximum 3 healthy deliveries per each infected pregnant woman (Figure 1). SARS CoV2 negative patient information collection used the same templates and same database as SARS CoV2 positive. The list of hospitals included in the study with their corresponding reported cases is in Appendix 1.

Information regarding the demographic characteristics of each pregnant woman, comorbidities and current obstetric history was extracted from the clinical history and from the interview with the patient; subsequently, age and race were categorized 
following the classification used by the CDC. ${ }^{13}$ Definitions of obstetric conditions followed international criteria. ${ }^{14-16}$ Perinatal events, medical and obstetric complications were recorded. Patients were followed until six weeks postpartum. Neonatal events were recorded until 14 days postpartum. A total of 33 dropout cases were recorded from the beginning of the registry; the reasons were incomplete information in the registry database, did not participate in the six-week postpartum follow-up and/or voluntary withdrawal of the patient.

\section{Data analysis}

For the descriptive analysis of the data, absolute and relative frequencies were used in the case of categorical variables and means and ranges in the case of quantitative variables. The possible association of both the characteristics of the patients and the outcomes collected with COVID infection was analysed using the Pearson's Chi-square test or Fisher's exact test and the Mann-Whitney U test (after checking the absence normality of the data using the Kolmogorov-Smirnov test). Statistical tests were twosided and were performed with SPSS V.20 (IBM Inc., Chicago, Il, USA); statistically significant associations were considered to exist when the p value was less than 0.05.

For computing measures of association of the outcomes of interest that were statistically significant in the univariate analysis (and with enough number of events) with COVID19 infection, the influence of known and suspected measured confounding factors was controlled for multivariate logistic regression modelling in order to derive adjusted odds ratios (aOR) with 95\% confidence intervals (95\% CI). Models were built for each outcome separately, incorporating a range of independent variables appropriate for the 
adjustment of the association between COVID-19 infection and that outcome. The selection process for variables was driven by causal knowledge for the adjustment of confounding, based on previous findings and clinical constraints. ${ }^{9,12-16}$ Besides COVID positivity, the preterm delivery model included Ethnicity [categorized as white European, Latin American and other ethnic groups (black non-Hispanic, Asian nonHispanic and Arab)], multiple pregnancy, in vitro fertilization, gestational hypertensive disorders (moderate or severe preeclampsia and HELLP), miscarriage risk and clinical and ultrasound prematurity screening; the spontaneous preterm delivery model included ethnicity (categorized as above), multiple pregnancy, miscarriage risk and clinical and ultrasound prematurity screening; the premature rupture of membranes at term (PROM) model included multiple pregnancy, miscarriage risk, cough, obesity $\left(\mathrm{BMI}>30 \mathrm{~kg} / \mathrm{m}^{2}\right.$ ) and smoking [categorized as smokers (actual and ex-smokers) and non-smokers]; the preterm premature rupture of membranes (PPROM) model included multiple pregnancy and miscarriage risk; and the neonate intensive care unit (NICU) admission model included multiple pregnancy, gestational hypertensive disorders and clinical and ultrasound prematurity screening as independent variables.

A complete list of the final set of covariates is provided with each model in the results section. The modelling was conducted after excluding cases with missing data. A prematurity screening program was not established in all participating hospitals and that variable had $11.3 \%$ of missing values, whereas the remaining variables had less than $1.2 \%$ of missing values. Regression analyses were carried out using lme4 package in $\mathrm{R}$, version 3.4 (RCoreTeam, 2017). ${ }^{17}$ 


\section{Results}

One thousand and nine $(1,009)$ patients who gave birth between $23^{\text {rd }}$ March and $31^{\text {st }}$ May were analysed: 246 cases and a healthy cohort of 763 pregnant women who were negative for the PCR test. Of the 246 positive cases, $88.6 \%(\mathrm{n}=218)$ were asymptomatic at delivery while $11.4 \%(n=28)$ were symptomatic. Of the asymptomatic women, $44(20.2 \%)$ had previously presented symptoms and $174(79.8 \%)$ were totally asymptomatic. On the other hand, of the pregnant women who showed symptoms at the time of delivery, $24(85.7 \%)$ cases corresponded to mild symptoms (being the most prevalent, cough $33.3 \%$, and anosmia $20.8 \%$, followed by fatigue/discomfort, fever and dyspnoea), 2 (7.1\%) pregnant women presented mild-moderate pneumonia and another $2(7.1 \%)$ pregnant women had developed severe pneumonia. No case of septic shock or maternal death was recorded in pregnant women with COVID-19 included in the study.

The demographic characteristics, comorbidities and current obstetric history of the positive cases and the healthy cohort (246 vs 763 ) are shown in Table 1 . The only variable in which statistically significant differences were observed was ethnicity, being significantly higher the proportion of Latin American women in the COVID-19 group ( $\mathrm{p}<0.001 ;$ OR $=2.85,95 \%$ CI: 1.96-4.15), while the opposite was true for White European patients $(\mathrm{p}<0.001, \mathrm{OR}=0.49,95 \%$ CI: 0.36-0.67). 
When the possible association of perinatal and neonatal events with COVID-19 was analysed by univariate and multivariate logistic regression using complete case analyses (without imputation for missing values) (Table 2 and 3), twice as many deliveries with less than 37 weeks of gestation were observed among the cases (13.8\%) than in the healthy group $(6.7 \%)(\mathrm{p}=0.002)$, with an adjusted OR equal to 2.12 (95\% CI: 1.32 3.36), although no statistically significant differences had been observed in the clinical and ultrasound screening for prematurity between both groups $(\mathrm{p}=0.461)$ (Table 1). Among preterm deliveries, iatrogenic preterm delivery (not associated with PPROM) was practically four times more frequent in infected pregnant women than in nonexposed (healthy) pregnant women ( $4.9 \%$ vs $1.3 \%, \mathrm{p}=0.001)$, while the occurrence of spontaneous preterm deliveries was not affected by COVID-19 status $(p=0.760$, adjusted $\mathrm{OR}=1.10,95 \% \mathrm{CI}: 0.57-2.06)($ Table 3$)$. In the exposed group, symptomatic COVID-19 were present in 5 (42\%) out of 12 iatrogenic preterm deliveries, while this was the case in only 3 (20\%) out of 15 spontaneous preterm deliveries.

Similarly, a higher risk of premature rupture of membranes, at term (PROM) and preterm (PPROM), was observed in the exposed group $(\mathrm{p}=0.009$ and $\mathrm{p}=0.031$, respectively) (Table 2). In the case of PROM, the finding of multivariate logistic regression was consistent with the above result, with a $70 \%$ increase of occurrence in the COVID-19 group compared to the non-exposed group (adjusted OR=1.70, 95\% CI:

\subsection{1-2.57) (Table 3).}


No maternal deaths were recorded in the 1,009 patients in the study, but there were intrauterine foetal deaths, with the proportion of these being considerably higher in patients with COVID-19 than in the non-exposed ones $(1.2 \%$ vs $0.1 \%, \mathrm{p}=0.047)$ (Table 2).

When the information regarding the neonate was analysed (Table 2 and 3), those born to mothers with COVID-19 were admitted to the NICU significantly more often than those born to healthy mothers ( $\mathrm{p}<0.001$, adjusted OR $=4.62,95 \%$ CI: $2.43-8.94$ ). Prematurity and respiratory distress were the main causes of NICU admission (Table 2), while none of these admissions were due to COVID-19 disease in newborns. In 189 (76.8\%) of the COVID-19 cases, a PCR analysis was performed on nasopharyngeal and/or oropharyngeal samples of the newborns; 147 were performed during the first 12 hours of life, three of which were positive, and another 42 were performed until 48 hours of life, all resulting negative. The 3 -initial positive newborns were retested at 48 hours, with final negative results.

\section{Discussion}

\section{Main findings}

To our knowledge, this is the first prospective cohort study to analyse whether a relationship exists between COVID-19 exposure and infection-related obstetric outcomes. We found, using multivariate models adjusting for confounding factors, that the pregnant women with COVID-19 had more preterm births, premature rupture of membranes at term and NICU admissions compared to the pregnant woman who were not exposed. 


\section{Strengths and weaknesses}

Ours is a cohort study carried out during a difficult pandemic situation whose continuing objective is to investigate the influence of COVID-19 on delivery and the puerperium. We wish to obtain the best epidemiological information in the shortest possible time with a follow-up 6 weeks after delivery. Patient recruitment continues in our registry and this is an initial analysis. Our work is one of the first prospective cohort studies to analyse the relationship between COVID-19 and prematurity. The relationship that we establish with premature rupture of membranes raises future lines of research.

The most important limitation of our work is the inability to compare infected patients with healthy patients from the beginning due to the lack of diagnostic tests and the health sector crisis that occurred. When a screening system was established, there were not as many patients with severe symptoms and the number of events reduced the ability to analyse some effects of symptomatic COVID-19. Many cases of obstetric severe preeclampsia, haemorrhage, pulmonary thromboembolism and abruptio occurred mainly in the months of March and April before many centres started screening programmes and the cohort study began, so no distinction has been made between the different clinical presentations of the disease. We could not do a multivariate analysis of such conditions.

No serological test was performed on patients who had a negative PCR test, either because the tests were not available at the time of recruitment or because they did not have a proven sensitivity. In some cases, these patients may have already had the disease. No serology was performed during those months on asymptomatic PCRpositive patients to confirm their disease and immune response. Our study is best understood if the results are interpreted under this premise and therefore our group 
continues to recruit patients to seek more associations, explanations and causations. This work reflects the conditions of patients with COVID-19 at the time of delivery and the puerperium. It has not analysed the course of the disease during pregnancy, nor has it recorded late abortions, vertical transmission, or causes of intrauterine mortality.

\section{Comparison with other studies}

The symptoms of the patients in our study do not differ from those already published. ${ }^{18,19}$ Although most did not have any symptoms, we did find an increase in obstetric pathology in these patients, which in our opinion indicates that in the pregnant woman with asymptomatic COVID-19 there is a specific obstetric pathology that needs to be recognised. In the same way as other authors, we have also found a demographic factor, such as ethnicity, that increases the possibility that a patient has COVID-19. ${ }^{13,20}$ It is necessary to know if there is a component of genetic susceptibility or if there are social factors that explain this association. There are already studies that relate this situation to less access to healthcare resources or the possibility of confinement which complies with healthcare measures. ${ }^{21}$

Patients with COVID-19 are at increased risk of preterm delivery associated with increased iatrogenic preterm delivery. The explanation for this risk is the need to end the pregnancy due to maternal diseases, such as severe pre-eclampsia and pneumonia, which are more frequent in these patients and lead to more labour inductions. A unique and novel finding in our study is the association between premature rupture of membranes at term and COVID-19. PROM may result in immediate risks and subsequent problems including maternal or neonatal infection. ${ }^{22}$ One of the possible explanations we found for this association is the activation of a series of mediators and biochemical pathways of inflammation in the premature rupture of membranes and premature delivery that are also found in COVID-19, such as macrophages or IL-6. ${ }^{23}$ 
The studies demonstrating the influence of IL- 6 on preterm delivery are a strong basis for studying this association. ${ }^{24}$ Cytokines are vital in regulating immunological and inflammatory responses. Among them, IL-6 is of major importance because there is evidence that circulating IL-6 levels are closely linked to the severity of the COVID-19 infection. ${ }^{25}$ There are already treatments that are indicated based on these findings. ${ }^{26}$

We observed a significant increase in the stillbirth rate in the univariate analysis alone. The role of inflammation mediators in these deaths could be the subject of a line of research because it is known that women without COVID-19 who have a pregnancy loss, have significantly higher amniotic fluid IL-6 concentration levels than those with a normal outcome. ${ }^{27}$ We found no differences in mortality or early or late neonatal morbidity related to COVID-19 between healthy and infected patients in our series, unlike reports from other series. ${ }^{28,29}$ There is a higher risk that the children of COVID19 mothers enter the NICU, with prematurity being one of the determining factors. All newborns were followed for at least 14 days by the different neonatology units of the participating hospitals, without any case of neonatal COVID-19 being detected in that period.

To date, there has been indirect evidence on placental involvement which would explain our findings. ${ }^{30,31}$ Our results derived using multivariate analyses confirm those of the cases series published at the beginning of the pandemic that described preterm deliveries and premature rupture of the membranes. ${ }^{18,28,32}$ 
medRxiv preprint doi: https://doi.org/10.1101/2020.09.05.20188458; this version posted September 7, 2020. The copyright holder for this preprint

(which was not certified by peer review) is the author/funder, who has granted medRxiv a license to display the preprint in perpetuity.

It is made available under a CC-BY-NC-ND 4.0 International license .

\section{Conclusion}

Pregnant COVID-19 patients are a population at risk of suffering preterm deliveries, and the disease has an impact on NICU admissions. Premature rupture of membranes at term and preterm are more frequent in patients with COVID-19. 
medRxiv preprint doi: https://doi.org/10.1101/2020.09.05.20188458; this version posted September 7, 2020. The copyright holder for this preprint

(which was not certified by peer review) is the author/funder, who has granted medRxiv a license to display the preprint in perpetuity.

It is made available under a CC-BY-NC-ND 4.0 International license .

\section{Acknowledgements}

Mr Jose Montes EFFICE.

Professor Khalid Khan for his scientific advice.

This study was fully funded with public funds obtained in competitive calls: grant COV20/00020 from the Institute of Health Carlos III and co-financed with FEDER funds. 


\section{REFERENCES}

1. Zhu N, Zhang D, Wang W, Xingwang L, Bo Y, Jingdong S, et al. A novel coronavirus from patients with pneumonia in China, 2019. N Engl J Med. 2020;382: 727-33. doi: 10.1056/NEJMoa2001017

2. Rasmussen SA, Smulian JC, Lednicky JA, Wen TS, Jamieson DJ. Coronavirus Disease 2019 (COVID-19) and pregnancy: what obstetricians need to know.Am J Obstet Gynecol. 2020 May; 222(5):415-426. doi: 10.1016/j.ajog.2020.02.017. Epub 2020

3. Panel Covid-19 en España [Internet]. Madrid: Centro Nacional de Epidemiología/Instituto de Salud Carlos III; 2001 [updated 2020 Jul 17; cited 2020 Jul 20]. Available from: https://cnecovid.isciii.es/covid19/

4. COVID-19 situation update worldwide. [Internet] Stockholm: European Centre for Disease Prevention and Control; 2005 [updated 2020 Jul 18; cited 2020 Jul 20]. Available from: https://www.ecdc.europa.eu/en/geographical-distribution-2019ncov-cases

5. Martínez-Perez O, Vouga M, Cruz Melguizo S, et al. Association Between Mode of Delivery Among Pregnant Women With COVID-19 and Maternal and Neonatal Outcomes in Spain. JAMA. Epub June 08, 2020. doi:10.1001/jama.2020.10125

6. WHO. Report of the WHO-China Joint Mission on Coronavirus Disease 2019 (COVID-19). Geneva; 16-24 February 2020. Avalaible from https://www.who.int/docs/default-source/coronaviruse/who-china-joint-mission-oncovid-19-final-report.pdf

7. Khalil A, von Dadelszen P, Draycott T, Ugwumadu A, O’Brien P, Magee L. Change in the Incidence of Stillbirth and Preterm Delivery During the COVID-19 Pandemic. JAMA. Epub July 10, 2020. doi:10.1001/jama.2020.12746 
8. Romero R, Munoz H, Gomez R, Sherer DM, Ghezzi F, Gibbs RS, et al.Two thirds of spontaneous abortion/fetal deaths after genetic amniocentesis are the result of a pre-existing sub-clinical inflammatory process of the amniotic cavity. Am J Obstet Gynecol 1995;172: S261

9. Liu Y, Chen H, Tang K, Guo Y. Clinical manifestations and outcome of SARS-CoV2 infection during pregnancy. J Infect. 2020 Mar 4. doi: 10.1016/j.jinf.2020.02.028. PMID: 32145216

10. Encinas Pardilla MB, Caño Aguilar Á, Marcos Puig B, Sanz Lorenzana A, Rodríguez de la Torre I, Hernando López de la Manzanara P, Fernández Bernardo A, Martínez Pérez O. Registro español de cribado de Covid-19 en gestantes asintomáticas. Rev Esp Salud Pública. 2020; 94. In press.

11. von Elm E, Altman DG, Egger M, Pocock SJ, Gotzsche PC, Vandenbroucke JP. The Strengthening the Reporting of Observational Studies in Epidemiology (STROBE) Statement: guidelines for reporting observational studies. Int J Surg 2014; 12:14959.

12. WHO. Clinical Management of COVID-19. Interim Guidance 27 May 2020. Geneva; 2020. WHO/2019-nCoV/clinical/2020.5. Available from: https://www.who.int/publications/i/item/clinical-management-of-covid-19

13. Ellington S, Strid P, Tong Van T, Woodworth K, Galang RG, Zambrano LD et al. Characteristics of Women of Reproductive Age with Laboratory-Confirmed SARSCoV-2 Infection by Pregnancy Status. MMWR Morb Mortal Wkly Rep 2020; 69(25): 769-775. $\quad$ Available from https://www.cdc.gov/mmwr/volumes/69/wr/pdfs/mm6925-H.pdf

14. Prelabor Rupture of Membranes: ACOG Practice Bulletin Summary, Number 217. Obstet Gynecol. 2020 Mar; 135(3): e80-e97. doi: 10.1097/AOG.0000000000003700 
15. Thomson, AJ, on behalf of the Royal College of Obstetricians and Gynaecologists.

Care of Women Presenting with Suspected Preterm Prelabour Rupture of Membranes from 24+ 0 to $36+6$ weeks of gestation. BJOG 2019; 126: e152-166. Available from $\quad$ https://www.rcog.org.uk/en/guidelines-researchservices/guidelines/gtg73/

16. Brown MA,Magee LA, Kenny LC, Karumanchi AS, McCarthy FP, Saito S, Hall DR, Warren CR, Adoyi G, Ishaku S on behalf of the International Society for the Study of Hypertension in Pregnancy (ISSHP). Hypertensive Disorders of Pregnancy, ISSHP Classification, Diagnosis, and Management Recommendations for International Practice. Hypertension 2018; 72(1):24-43. Available from: https://doi.org/10.1161/HYPERTENSIONAHA.117.10803

17. Douglas Bates, Martin Maechler, Ben Bolker, Steve Walker (2015). Fitting Linear Mixed-Effects Models Using lme4. Journal of Statistical Software, 67(1), 1-48. doi:10.18637/jss.v067.i01.

18. Chen H, Guo J, Wang C, Luo F, Yu X, Zhang W et al.Clinical characteristics and intrauterine vertical transmission potential of COVID-19 infection in nine pregnant women: a retrospective review of medical records. Lancet; 395 (10226): 809 815doi: https://doi.org/10.1016/S0140-6736(20)30360-3

19. Richardson S, Hirsch JS, Narasimhan M, Crawford JM, McGinn T, Davidson KW; and the Northwell COVID-19 Research Consortium, Barnaby DP, Becker LB, Chelico JD, Cohen SL, Cookingham J, Coppa K, Diefenbach MA, Dominello AJ, Duer-Hefele J, Falzon L, Gitlin J, Hajizadeh N, Harvin TG, Hirschwerk DA, Kim EJ, Kozel ZM, Marrast LM, Mogavero JN, Osorio GA, Qiu M, Zanos TP. Presenting Characteristics, Comorbidities, and Outcomes Among 5700 Patients 
Hospitalized With COVID-19 in the New York City. JAMA 2020;323(20):20522059. doi:10.1001/jama.2020.6775

20. Knight M, Bunch K, Vousden N, Morris E, Simpson N, Gale C et al.on behalf of the UK Obstetric Surveillance System SARS-CoV-2 Infection in Pregnancy Collaborative Group. Characteristics and outcomes of pregnant women admitted to hospital with confirmed SARS-CoV-2 infection in UK: national population-based cohort study Obstetric Surveillance System SARS-CoV. BMJ 2020; 369:m2107. https://doi.org/10.1136/bmj.m2107

21. W M; Napoles A; Pérez-Stable E. COVID-19 and Racial/Ethnic DisparitiesJAMA. 2020; 323(24):2466-2467. doi:10.1001/jama.2020.8598

22. Alexander JM, Cox SM. Clinical course of premature rupture of the membranes. Semin Perinatol. 1996 Oct; 20(5):369-74. doi: 10.1016/s0146-0005(96)80003-6. PMID: 8912990

23. Lannon SMR, Vanderhoeven JP, Eschenbach DA, Gravett MG, Adams Waldorf K A.Synergy and Interactions Among Biological Pathways Leading to Preterm Premature Rupture of Membranes. Reprod.Sci.2014; 21(10):1215-1227. https://doi.org/10.1177/1933719114534535

24. Romero R, Yoon BH, Kenney JS, Gomez R, Allison AC, Sehgal PB. Amniotic fluid interleukin-6 determinations are of diagnostic and prognostic value in preterm labor. Am J Reprod Immunol. 1993; 30(2-3):167-83. doi: 10.1111/j.16000897.1993.tb00618.x. PMID: 8311926

25. Aziz M, Fatima R, Assaly R. Elevated interleukin-6 and severe COVID-19: A metaanalysis. J Med Virol. 2020 Apr 28:10.1002/jmv.25948. doi: 10.1002/jmv.25948. Epub ahead of print. PMID: 32343429; PMCID: PMC7267383. 
26. Naqvi M, Zakowski P, Glucksman L, Smithson S, Burwick RM. Tocilizumab and Remdesivir in a Pregnant Patient with Coronavirus Disease 2019 (COVID-19). Obstet Gynecol. 2020 Jun 30. doi: 10.1097/AOG.0000000000004050. PMID: 32618794

27. Wenstrom KD, Andrews WW, Tamura T, DuBard MB, Johnston KE,Hemstreet GP. Elevated amniotic fluid interleukin-6 levels at genetic amniocentesis predict subsequent pregnancy loss. Am J Obstet Gynecol 1996; 175:830-3

28. Zhang L, Jiang Y, Wei M, Cheng BH, Zhou XC, Li J, Tian JH, Dong L, Hu RH. Analysis of the pregnancy outcomes in pregnant women with COVID-19 in Hubei Province. Zhonghua Fu Chan Ke Za Zhi. 2020 Mar 25;55(3):166-171. Chinese. doi: 10.3760/cma.j.cn112141-20200218-00111. PMID: 32145714

29. Chen Y, Peng H, Wang L, Zhao Y, Zeng L, Gao H, et al. Infants born to mothers with a new coronavirus (COVID-19) Front Pediatr. 2020; 8:1-5. doi: 10.3389/fped.2020.00104

30. Prochaska E, Minyoung J, Burd I. COVID-19 in pregnancy: Placental and neonatal involvement. Am J Reprod Immunol2020 Jul 17; e13306. doi: 10.1111/aji.13306.

31. Shanes ED, Mithal LB, Otero S, Azad HA, Miller ES, Goldstein JA. Placental Pathology in COVID-19. Am J Clin Pathol 2020; 154:23-32. Available from: https://doi.org/10.1093/ajcp/aqaa089

32. Zhu H, Wang L, Fang C, et al. Clinical analysis of 10 neonates born to mothers with 2019-nCoV pneumonia. Transl Pediatr. 2020; 9(1). doi: 10.21037/tp. 2020.02.06 


\section{TABLES AND FIGURES}

Figure 1: Study Flow chart

Table 1: Patient demographic characteristics, comorbidities and current obstetric history in a pregnancy cohort screened for COVID-19.

Table 2: Maternal and neonatal outcomes in pregnant women screened for COVID-19

Table 3: Odds ratio (OR) and adjusted odds ratio (aOR) with the corresponding 95\% confidence intervals and p-values for the obstetric outcomes associated with exposure to COVID-19 in pregnancy. 
65 hospitals with positive cases of COVID-19 in pregnant women from 1st March to 31st May $2020^{a}$
11 hospitals without positive cases of COVID-19 in pregnant women in the same period
20 hospitals

without consecutive universal PCR screening

\section{5 hospitals}

with consecutive universal PCR screening

screening starting date: 23 rd March 2020

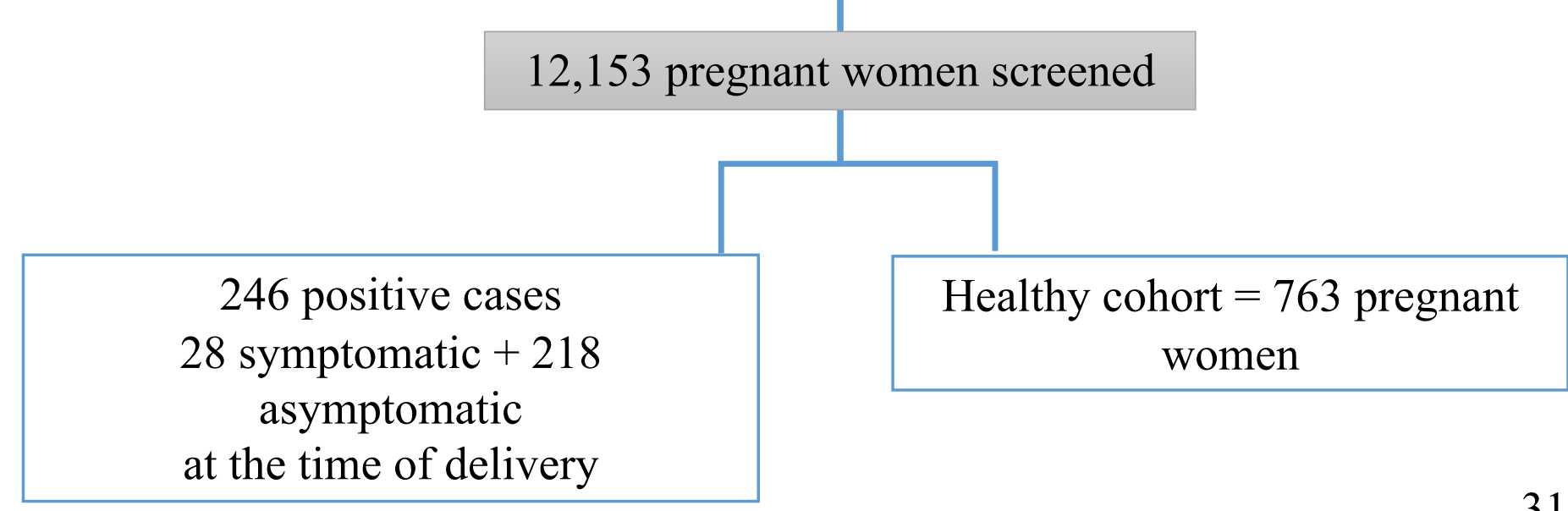

31st May 2020 
Table 1. Patient demographic characteristics, comorbidities and current obstetric history in a pregnancy cohort screened for COVID-19.

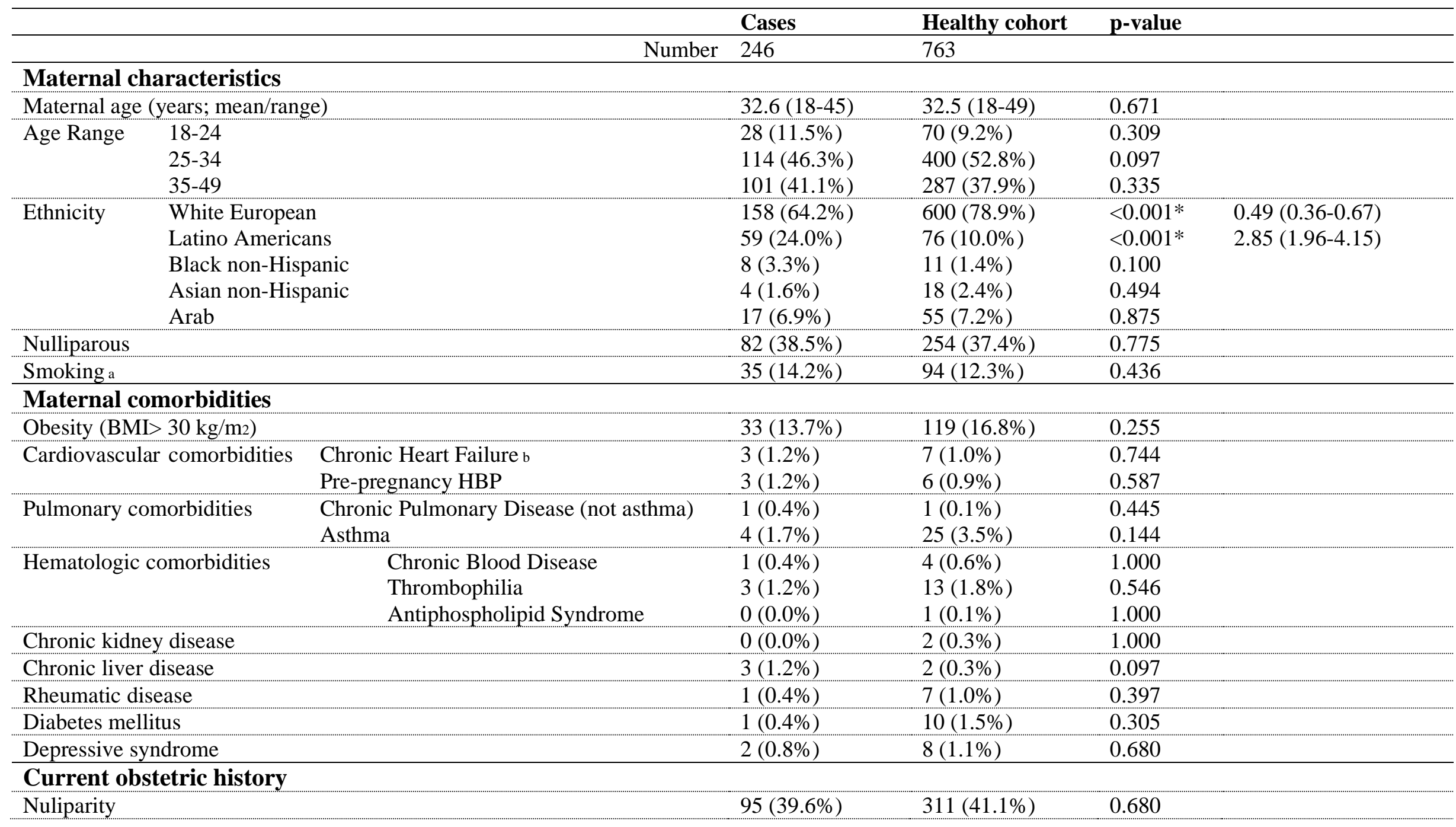




\begin{tabular}{|c|c|c|c|}
\hline Multiple pregnancy & $6(2.4 \%)$ & $31(4.1 \%)$ & 0.239 \\
\hline In Vitro Fertilization & $15(6.1 \%)$ & $27(3.5 \%)$ & 0.081 \\
\hline Haemoglobin $<10$ g/dL & $6(2.5 \%)$ & $39(5.4 \%)$ & 0.065 \\
\hline Platelets $<100,000 / \mu \mathrm{L}$ & $3(1.2 \%)$ & $2(0.3 \%)$ & 0.104 \\
\hline Pregnancy-induced hypertension $\mathrm{c}$ & $12(4.9 \%)$ & $34(4.8 \%)$ & 0.962 \\
\hline Gestational diabetes & $17(7.0 \%)$ & $61(8.4 \%)$ & 0.476 \\
\hline Intrauterine growth restriction & $13(5.3 \%)$ & $27(3.8 \%)$ & 0.303 \\
\hline High Risk Preeclampsia Screening & $8(3.7 \%)$ & $38(5.8 \%)$ & 0.230 \\
\hline High-risk Chromosomal Abnormality Screening & $4(1.7 \%)$ & $18(2.6 \%)$ & 0.428 \\
\hline Clinical and Ultrasound Prematurity Screening & $5(2.3 \%)$ & $21(3.3 \%)$ & 0.461 \\
\hline Miscarriage risk & $11(4.5 \%)$ & $17(2.2 \%)$ & 0.062 \\
\hline
\end{tabular}

Data are shown as n (\% of total), except where otherwise indicated.

OR: odds ratio; CI: confidence interval; BMI: Body Mass Index; HT: Hypertension

*Statistically significant differences: OR and 95\% CI were estimated

a Current smoker and ex-smoker

b Including Congenital Heart Disease, not HT

c HT + preeclampsia 
Table 2. Maternal and neonatal outcomes in pregnant women screened for COVID-19

\begin{tabular}{|c|c|c|c|}
\hline & Cases & Healthy cohort & p-value \\
\hline Number & 246 & 763 & \\
\hline \multicolumn{4}{|l|}{ Perinatal outcome } \\
\hline Gestational age at delivery (weeks+days; mean/range) & $38+4(27-42)$ & $39+0(23-42)$ & 0.010 \\
\hline Type of delivery $\quad$ Cesarean & $55(22.4 \%)$ & $143(18.7 \%)$ & 0.214 \\
\hline Eutocic & $170(69.1 \%)$ & $506(66.3 \%)$ & 0.419 \\
\hline Instrumental & $21(8.5 \%)$ & $114(14.9 \%)$ & 0.010 \\
\hline Preterm deliveries (<37 weeks of gestational age) & $34(13.8 \%)$ & $51(6.7 \%)$ & 0.001 \\
\hline $\begin{array}{l}\text { Preterm deliveries ( } 3 / \text { weeks of gestational age) } \\
\text { Spontaneous delivery }\end{array}$ & $15(6.1 \%)$ & $36(4.7 \%)$ & 0.390 \\
\hline Iatrogenic delivery & $19(7.7 \%)$ & $15(2.0 \%)$ & 0.001 \\
\hline Iatrogenic delivery (no PPROM) & $12(4.9 \%)$ & $10(1.3 \%)$ & 0.001 \\
\hline \multicolumn{4}{|l|}{ Causes of preterm iatrogenic delivery (no PPROM): } \\
\hline COVID-19 mild symptoms & $3 / 12$ & $0 / 10$ & \\
\hline Pneumonia & $3 / 12$ & $0 / 10$ & \\
\hline Severe preeclampsia & $4 / 12$ & $1 / 10$ & 0.323 \\
\hline PROM & $39(15.8 \%)$ & $75(9.8 \%)$ & 0.009 \\
\hline (a & $11(4.5 \%)$ & $15(2.0 \%)$ & $\mathbf{0 . 0 3 1}$ \\
\hline Gestational age at PPROM (weeks+days; mean/range) & $33+5(28-36)$ & $33+6(28-36)$ & 0.610 \\
\hline \multicolumn{4}{|l|}{ Medical and obstetrical complications } \\
\hline Admitted in ICU & $5(2.0 \%)$ & $2(0.3 \%)$ & 0.011 \\
\hline Days in ICU (mean/range) & $9.5(6-14)$ & $2(2-2)$ & \\
\hline
\end{tabular}




\begin{tabular}{|c|c|c|c|}
\hline \multicolumn{4}{|l|}{ Obstetrical complications } \\
\hline Hemorrhagic events & $10(4.1 \%)$ & $34(4.5 \%)$ & 0.794 \\
\hline Abruptio placentae & $2(0.8 \%)$ & $1(0.1 \%)$ & 0.149 \\
\hline Postpartum hemorrhage & $8(3.3 \%)$ & $33(4.3 \%)$ & 0.459 \\
\hline Gestational hypertensive disorders & $11(4.5 \%)$ & $44(5.8 \%)$ & 0.436 \\
\hline Severe preeclampsia & $6(2.4 \%)$ & $3(0.4 \%)$ & 0.008 \\
\hline Admitted in ICU & $2 / 6$ & $0 / 3$ & \\
\hline Invasive ventilation & $0 / 6$ & $0 / 7$ & \\
\hline Moderate preeclampsia & $5(2.0 \%)$ & $41(5.4 \%)$ & 0.025 \\
\hline \multicolumn{4}{|l|}{ Neonatal data } \\
\hline Apgar 5 score $<7$ & $5(2.0 \%)$ & $8(1.1 \%)$ & 0.325 \\
\hline Umbilical artery $\mathrm{pH}<7.10$ & $6(3.0 \%)$ & $24(3.8 \%)$ & 0.608 \\
\hline Admitted in NICU & $23(9.3 \%)$ & $18(2.4 \%)$ & 0.001 \\
\hline Days in NICU (mean/range) & $13.8(1-48)$ & $10.7(2-26)$ & 0.379 \\
\hline \multicolumn{4}{|l|}{ Cause of NICU admission: } \\
\hline Prematurity & $15 / 23$ & $12 / 18$ & \\
\hline Respiratory distress & $2 / 23$ & $6 / 18$ & \\
\hline Neonatal COVID-19 PCR testing within the first 48 hours & $196(79.7 \%)$ & $0(0.0 \%)$ & \\
\hline Stillbirth & $3(1.2 \%)$ & $1(0.1 \%)$ & 0.047 \\
\hline Neonatal mortality & $0(0.0 \%)$ & $1(0.1 \%) \mathrm{a}$ & 1.000 \\
\hline \multicolumn{4}{|l|}{6 weeks mother follow-up } \\
\hline Mastitis & $1(0.4 \%)$ & $1(0.1 \%)$ & 0.428 \\
\hline \multicolumn{4}{|l|}{14 days neonate follow-up } \\
\hline Readmission due to COVID-19 & $0(0.0 \%)$ & $0(0.0 \%)$ & \\
\hline
\end{tabular}

Data are shown as $\mathrm{n}$ (\% of total), except where otherwise indicated.

COVID-19: Coronavirus disease 2019; PROM: Premature rupture of membranes; PPROM: Preterm Premature Rupture of Membranes; ICU: Intensive care unit; NICU: Neonatal intensive care unit.

a Prematurity causes, gestational age at delivery was 24 weeks 
Table 3. Odds ratio (OR) and adjusted odds ratio (aOR) with the corresponding 95\% confidence intervals and $p$-values for the obstetric outcomes associated with exposure to COVID-19 in pregnancy.

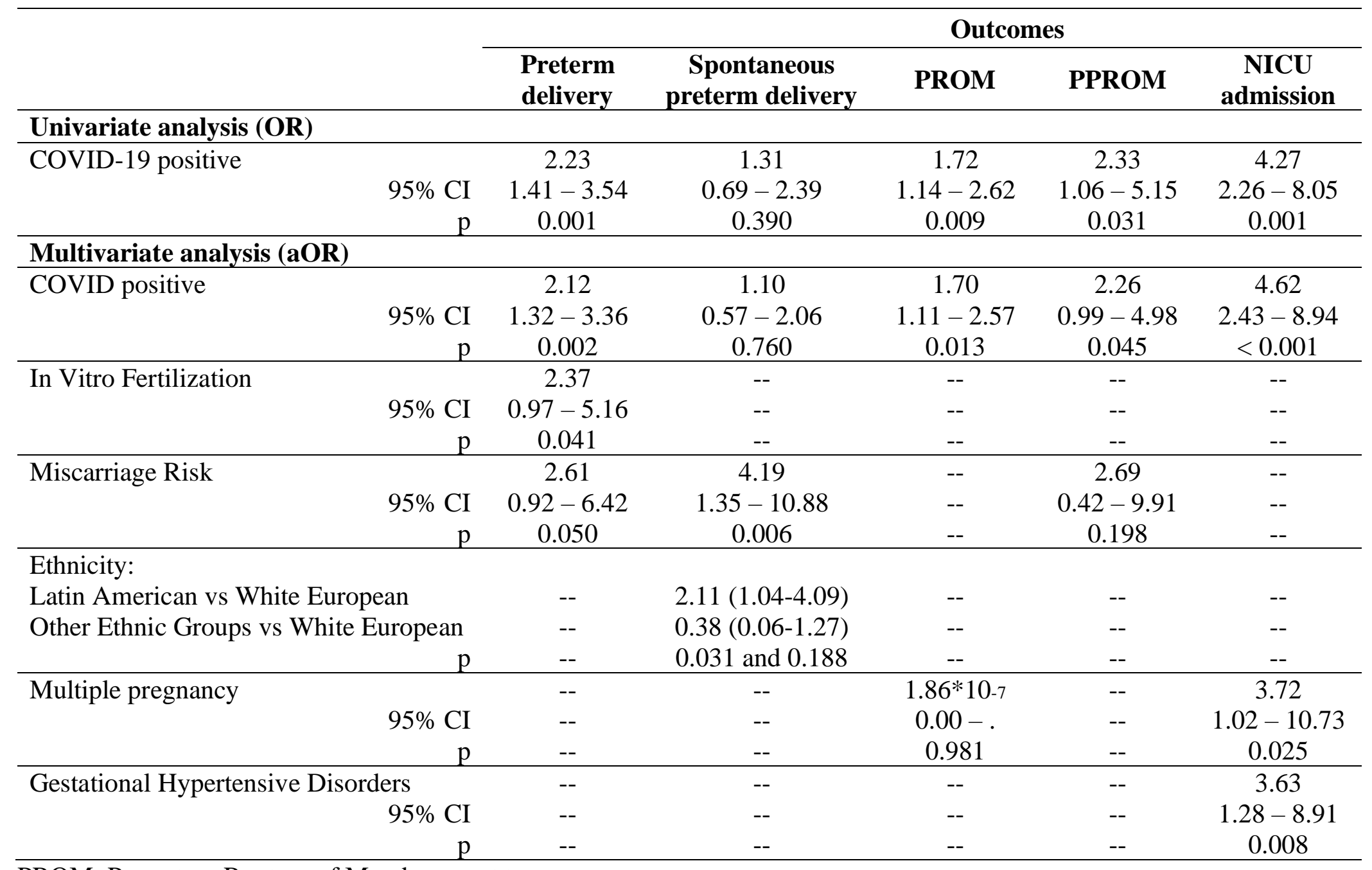

PROM: Premature Rupture of Membranes at term

PPROM: Preterm Premature Rupture of Membranes

NICU: Neonatal Intensive Care Unit 
Multivariable logistic regression used for each outcome as dependent variable and COVID-19 exposure in pregnancy and known/suspected confounding variables as independent variables (see Methods for details).

-- Variables not included or not held in the multivariate model 